\title{
The Role of Fish Oil in Psoriasis
}

\section{A Randomized, Double-Blind, Placebo-Controlled Study to Evaluate the Effect of Fish Oil and Topical Corticosteroid Therapy in Psoriasis}

\author{
Aditya K. Gupta, M.D., F.R.C.P.(C), Charles N. Ellis, M.D., Michael T. Goldfarb, M.D., \\ Ted A. Hamilton, M.S., AND JOhN J. VoOrhees, M.D.
}

ABSTRACT: In a randomized, double-blind, placebo-controlled study, patients received 10 fish or olive oil capsules three times daily for the whole study in addition to applying betamethasone diproprionate to their psoriatic plaques for the first 3 weeks. Most patients gradually worsened upon discontinuation of corticosteroids. Using survival analysis methods, no significant difference was found between the fish and olive oil groups. The authors attempt to put the role of fish oil in the therapy of psoriasis into perspective and discuss the efficacy of fish oil when used alone versus in combination therapy.

$\mathrm{T}$ here has been recent interest in the role of dietary fish oils (omega-3 polyunsaturated fatty acids) in the protection against certain conditions. These include cardiovascular disease, ${ }^{1}$ inflammatory conditions $^{2}$ (eg, rheumatoid arthritis), and cutaneous diseases $^{3-10}$ (psoriasis and atopic dermatitis) (Table 1). Polyunsaturated fatty acids (PUFAs) can be divided into three main groups: omega- 3 fatty acids derived mainly from marine oils, omega- 6 fatty acids found principally in vegetable oils (Fig. 1), and omega-9 fatty acids obtained mainly from animals.

In the epidermis of psoriatic plaques, levels of arachidonic acid (AA) and its metabolites are markedly elevated compared to clinically uninvolved skin. ${ }^{11}$ In particular, metabolites of the 5- and 12-lipoxygenase pathways such as leukotriene $B_{4}\left(L_{T} B_{4}\right)$ and 12 hydroxyeicosatetraenoic (12 HETE) acid, both of which are chemotactic for neutrophils, are thought to

Supported in part by the Babcock Endowment Fund.

Address correspondence to: Aditya K. Gupta, M.D., F.R.C.P.(C), Department of Dermatology, University of Michigan Medical Center, Room 1910TC, 1500 E. Medical Center Drive, Ann Arbor, MI 48109-0314.
From the Department of Dermatology, University of Michigan Medical Center, Ann Arbor, Michigan

play a role in psoriasis. When exogenous supplements of omega-3 PUFAs are consumed for the treatment of psoriasis, they are incorporated into cell membranes and compete with omega-6 PUFAs as substrates for the same 5-, 12-, and 15-lipoxygenase and cyclooxygenase pathways (Fig. 1). This results in the increased production of less biologically active leukotrienes (LTs) of the 5-series, prostaglandins (PGs) of the 3series, and 12 HEPE, with a decreased production of the LTs of the 4-series, PGs of the 2-series, and 12 HETE. ${ }^{12}$ Prostaglandins are involved in the feedback regulation of interleukin-1 (IL-1). ${ }^{13}$ IL-1 may be involved in keratinocyte proliferation ${ }^{14}$ and is markedly dysregulated in psoriasis. ${ }^{15}$ Because the antiinflammatory effects of omega-3 PUFAs may be due to decreased mononuclear cell IL- 1 production, ${ }^{16}$ omega- 3 PUFAs might affect the dysregulated IL-1 production by psoriatic keratinocytes.

In the past we have been able to achieve only modest improvement in psoriasis using a relative high dose of eicosapentaenoic acid (EPA, 10.8-13.5 g/day) as a monotherapy with strict dietary control. Fish oil appears to be more effective as a combination therapy with ultraviolet $B^{7,8}$ (Table 1 ). We decided to investigate whether fish oil would be more beneficial in combination with other standard therapies for psoriasis, compared to monotherapy. A double-blind, randomized, placebo-controlled study was therefore performed in which we used fish oil at a lower dose than our earlier study (EPA, $5.4 \mathrm{~g} /$ day) with a moderate potency corticosteroid (betamethasone dipro- 
TAble 1. Studies Evaluating the Efficacy of Fish Oil in Psoraisis

\begin{tabular}{|c|c|c|c|c|c|c|}
\hline Study & Study Design & $\begin{array}{l}\text { Duration } \\
\text { (Weeks) }\end{array}$ & $\begin{array}{c}\text { Daily } \\
\operatorname{EPA}^{*}(G)\end{array}$ & $\begin{array}{c}\text { Dietary } \\
\text { Intervention }\end{array}$ & $\begin{array}{c}\text { Other } \\
\text { Combination } \\
\text { Therapy }\end{array}$ & Outcome \\
\hline $\begin{array}{l}\text { Ziboh et al. }^{3} \\
\qquad(\mathrm{n}=13)\end{array}$ & Open & 8 & $10.8-13.5$ & Yes & No & Mild-moderate improvement \\
\hline $\begin{array}{l}\text { Maurice et al. }{ }^{4} \\
\qquad(n=10)\end{array}$ & Open & 6 & 12 & Yes & No & $\begin{array}{l}\text { Modest improvement, particularly decrease } \\
\text { in erythema and scaling }\end{array}$ \\
\hline 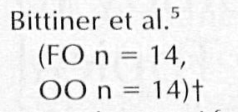 & $\begin{array}{l}\text { Double-blind, } \\
\text { placebo- } \\
\text { controlled }\end{array}$ & 8 & 1.8 & No & No & $\begin{array}{l}\text { Decrease in TBSA, erythema, and pruritus; } \\
\text { No change in scaling }\end{array}$ \\
\hline $\begin{array}{c}\text { Bjorneboe et } \text { al. }^{6} \\
(\mathrm{FO} n=13 \\
\text { OO } n=14)\end{array}$ & $\begin{array}{l}\text { Double-blind, } \\
\text { placebo- } \\
\text { controlled }\end{array}$ & 8 & 1.8 & No & No & No improvement \\
\hline $\begin{array}{l}\text { Kettler et al. }{ }^{7} \\
\quad(n=23)\end{array}$ & Open & $6-8$ & 3.2 & No & $\begin{array}{l}\text { Yes UBV in } 4 \\
\text { patients }\end{array}$ & $\begin{array}{l}\text { Plaque psoriasis: } \\
\text { Fish oil alone }(n=17) \text {; no significant } \\
\text { improvement; Fish oil plus UVB }(n=14) \text {; } \\
\text { minimal improvement } \\
\text { Pustular psoriasis: } \\
\text { Fish oil alone }(n=1) \text {; marked improvement } \\
\text { Palmoplantar pustulosis: } \\
\text { Fish oil alone }(n=1) \text {; no change }\end{array}$ \\
\hline $\begin{array}{l}\text { Gupta et al. } \\
\qquad \begin{array}{l}\text { (FO } n=8 \\
\text { OO } n=10)\end{array}\end{array}$ & $\begin{array}{l}\text { Double-blind, } \\
\text { placebo- } \\
\text { controlled }\end{array}$ & 15 & 3.6 & No & $\begin{array}{l}\text { UVB in all } \\
\text { patients } \neq\end{array}$ & $\begin{array}{l}\text { Modest improvement in all parameters of } \\
\text { skin disease, TBSA, scale, erythema, and } \\
\text { thickness. }\end{array}$ \\
\hline $\begin{array}{l}\text { Kragballe et al. }{ }^{9} \\
\qquad(\mathrm{FO} \mathrm{n}=30)\end{array}$ & Open & 12 & 5.4 & Yes & No & $\begin{array}{l}26 \text { patients completed study; none or mild } \\
\text { improvement }-11 \text { patients, moderate } \\
\text { improvement }-13 \text {, excellent }-2\end{array}$ \\
\hline $\begin{array}{l}\text { Present study } \\
\qquad \begin{array}{l}\text { (FO } n=8 \\
\text { OO } n=10)\end{array}\end{array}$ & $\begin{array}{l}\text { Double-blind, } \\
\text { placebo- } \\
\text { controlled }\end{array}$ & 9 & 5.4 & No & $\begin{array}{l}\text { Corticosteroids in } \\
\text { all patients (see } \\
\text { text) }\end{array}$ & See text \\
\hline
\end{tabular}

* $\mathrm{EPA}=$ Eicosapentaenoic acid.

$+\mathrm{FO}=$ Fish oil, $\mathrm{OO}=$ olive oil.

‡ 15 week study; 20 oil (fish or olive) capsules daily for 15 weeks. Between weeks $4-11$ of study, all patients also received suberythemal doses of UVB

prionate cream, Stoughton-Cornell assay group 3) without dietary control.

\section{Methods}

Twenty-five adults with stable plaque type psoriasis (15-66\% total body surface area [TBSA] involvement) entered the study. All patients had been without oral and topical medications (other than emollients) for their psoriasis for 4 and 2 weeks, respectively. During the study period, patients followed their normal dietary patterns. Exclusion criteria for entry into the study included patients with guttate psoriasis, those with less than 10\% TBSA involvement, and pregnant and lactating women. The protocol had been approved by our institutional review board, and informed consent was obtained from each patient.

Study subjects were randomly assigned to the fish or placebo oil groups and received 10 oil capsules tid. The daily intake of fish oil (Max-EPAR, R. P. Scherer, Troy, MI) included $5.4 \mathrm{gm}$ of EPA and $3.6 \mathrm{gm}$ of docosahexaenoic acid (DCHA). The identical looking olive oil capsules (R. P. Scherer, Troy, MI) contained 0 gm EPA and DCHA, 76\% oleic acid, 9\% palmitic acid, 7\% linoleic acid, and 2\% stearic acid. In addition to the oil therapy, patients applied emollients to uninvolved areas and psoriatic skin 2 or 3 times/day throughout the study.

Return visits were once weekly for the first 3 weeks and then every 2 weeks. Patients were considered to have completed the study after 9 weeks of oil therapy or when their global severity score had worsened to the pretherapy level. The extent of psoriasis was determined by measuring the TBSA at each visit. The global severity and individual parameters of scale, erythema, and thickness were each measured on a 6 -point scale $(0=$ absent, $1=$ trace, $2=$ mild, 3 $=$ mild-moderate, 4 = moderate, $5=$ moderate-severe, and $6=$ severe). For the first 3 weeks only, both groups applied betamethasone diproprionate ( $45 \mathrm{~g} /$ week) to the plaques of psoriasis twice daily. All patients demonstrated improvement at the end of corticosteroid therapy. Students twosample t-test was used to assess the difference between the 2 groups at baseline and week 3 . The second phase of the study (after week 3) was designed to test the hypothesis that fish oil may act beneficially and maintain or enhance the improvement achieved by corticosteroids. This hypothesis was tested by determining the respective Kaplan-Meier survival curve for each group and then testing the equality of the two curves with the Mantel-Cox test. The length of treatment survival for each patient was defined as the time from discontinuation of the betamethasone cream to the 
Fig. 1. Pathways along which $w-3$ and $w-6$ fatty acids are metabolized. Nomenclature: 18:2n6; 18 indicates the number of carbon atoms in the molecule, 2 refers to the number of double bonds, 6 denotes the location of the first double bond counting from the methyl end, $\mathrm{n}$ is an alternative symbol for w. Abbreviations: TX, thromboxane; PG, prostaglandin; LT, leukotriene; HETE, hydroxyeicosatetraenoic acid; HEPE, hydroxyeicosapentaenoic acid.
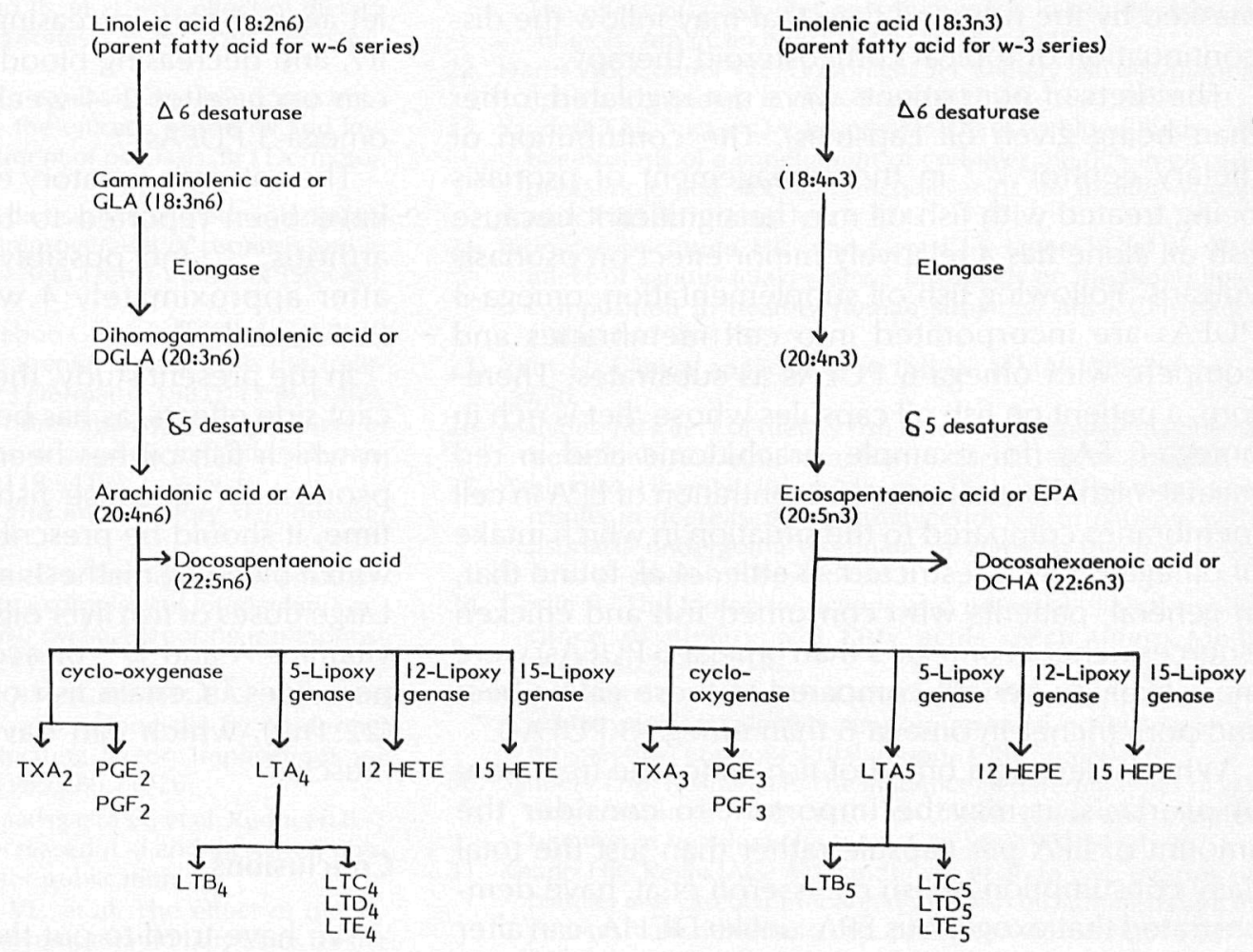

time when the patient fully regressed to the pretherapy state on the global scale. Patients who never regressed to pretherapy severity by the end of the study (week 9) were treated as censored observations. The survival analysis was carried out with the BMDP PIL statistical software program (BMDP Statistical Software; Los Angeles, CA). Means are reported with a confidence interval of \pm 1 standard error (SE). All $p$ values are two-sided.

\section{Results}

Ten patients ( 6 men and 4 women) with a mean age of 37 years (range, 21-61) received fish oil. Their pretherapy global severity score and TBSA was 5.0 \pm 0.2 and $35.5 \pm 4.7 \%$, respectively. Fifteen patients ( 8 men and 7 women) with a mean age of 47 years (range, 26-72) received placebo olive oil. In this group, the pretherapy global severity score and TBSA were $4.6 \pm 0.2$ and $32.9 \pm 1.8 \%$, respectively. The severity of psoriasis in the two groups was not significantly different from each other at pretherapy.

After 3 weeks of betamethasone therapy, there was equivalent improvement of the psoriasis in both the fish and olive oil groups. After discontinuation of corticosteroids, the mean time period elapsed before the psoriasis. worsened to pretherapy severity was 4.9 \pm 0.5 weeks in the fish oil group and $4.5 \pm 0.3$ weeks in the olive oil group ( $p=0.4)$. The psoriasis did not regress to pretherapy severity by the end of the study (week 9) in three patients in each of the fish and olive oil groups. Side effects included an occasional fishy taste upon eructation in one patient on fish oil and one on olive oil therapy. There was transient diarrhea at beginning of therapy in 2 patients on fish oil. No patient complained of bloating of the abdomen or a fishy smell upon flatulence.

There was one drop out in the fish oil group from lack of compliance. In the olive oil group there were five dropouts: 2 because of lack of improvement, 2 because of lack of compliance, 1 because of nonrelated medical problems.

\section{Comment}

When used as a monotherapy, studies using fairly large doses of EPA (10.8-13.5 g/day) demonstrated minimal to modest improvement; ${ }^{3,4}$ however, studies using a lower dose of EPA ( $1.8 \mathrm{~g} /$ day) have demonstrated considerably less improvement in some of the parameters of psoriasis disease activity (Table 1). With combined fish oil and UVB therapy, minimal to modest improvement in psoriasis was reported at lower doses of EPA (3.2-3.6 g/day). ${ }^{7.8}$ In the present study, fish oil (5.4 g EPA daily) did not have a significant beneficial effect and most patients gradually worsened upon discontinuation of topical corticosteroids. It is possible that improvement might have occurred with higher doses of fish oil. Another possibility is that any modest improvement from fish oil therapy was 
masked by the rebound flare that may follow the discontinuation of topical corticosteroid therapy.

The diets of our patients were not regulated (other than being given oil capsules). The contribution of dietary control ${ }^{3,4,7,9}$ in the management of psoriasis being treated with fish oil may be significant because fish oil alone has a relatively minor effect on psoriasis vulgaris. Following fish oil supplementation, omega-3 PUFAs are incorporated into cell membranes and compete with omega-6 PUFAs as substrates. Therefore, a patient on fish oil capsules whose diet is rich in omega-6 FAs (for example, arachidonic acid in red meats) might have a lower concentration of EPA in cell membranes compared to the situation in which intake of omega- 6 FAs is restricted. ${ }^{7}$ Kettler et al. found that, in general, patients who consumed fish and chicken (sources richer in omega-3 than omega-6 PUFAs) were more likely to benefit compared to those eating beef and pork (richer in omega-6 than omega-3 PUFAs). ${ }^{\text {? }}$

When selecting a brand of fish oil for the treatment of psoriasis, it may be important to consider the amount of EPA per capsule rather than just the total daily consumption of fish oil. Isseroff et al. have demonstrated that exogenous EPA, unlike DCHA, can alter the proliferation of keratinocytes and normalize the pattern of differentiation. ${ }^{2}$ Thus the degree of benefit derived may be dependent upon the total daily EPA consumption.

Fish oils have been reported to have various general beneficial effects. Singer et al. ${ }^{17}$ found that a mackerel diet ( $2.2 \mathrm{~g} /$ day of EPA) for 2 weeks resulted in a significant lowering of blood pressure. This lowering effect on blood pressure has also been confirmed by others. ${ }^{18}$ Fish oil supplementation can play a role in the reduction of two common side effects of cyclosporin A therapy, hypertension, and nephrotoxicity. ${ }^{19}$

These cyclosporin A-induced effects may occur in part as a result of increased production of vasconstrictive mediators such as $\mathrm{TXA}_{2}, \mathrm{PGE}_{2}$, and prostacyclin $\mathrm{I}_{2}\left(\mathrm{PI}_{2}\right)$. Fish oil may result in a net decrease of the above, with production of the more vasodilatory $\mathrm{TXA}_{3}, \mathrm{PGE}_{3}$, and $\mathrm{Pl}_{3} .^{20}$

Omega-3 PUFAs can lower serum triglycerides and cholesterol in hyperlipidemic and normal subjects in a dose-dependent fashion, with a greater effect on the triglyceride levels than cholesterol. ${ }^{21-25}$ Fish oil supplementation (3-4.5 g/day of omega-3 FA containing 1.8-2.6 g EPA) given for 4 weeks has been helpful in reducing retinoid induced hyperlipidemia. ${ }^{26,27}$ This may be particularly important in patients on long-term retinoid therapy.

Other beneficial effects of fish oil include a reduction in coronary heart disease. ${ }^{28}$ This may be the result of fish oils prolonging bleeding time, inhibiting plate- let aggregation, increasing red blood cell deformability, and decreasing blood viscosity. ${ }^{29-33}$ These effects can occur after 2-4 weeks of therapy with $2-4 \mathrm{~g}$ of omega-3 PUFAs. ${ }^{28}$

The anti-inflammatory effects of fish oil therapy also have been reported to be beneficial in rheumatoid arthritis ${ }^{34,35}$ and possibly in asthma. ${ }^{36}$ These occur after approximately 4 weeks of $4 \mathrm{gm}$ of omega- 3 PUFAs daily. ${ }^{28}$

In the present study, there were no clinically significant side effects, as has been the case in other studies in which fish oil has been used for the treatment of psoriasis. ${ }^{3-9}$ Because fish oil can prolong bleeding time, it should be prescribed with caution in patients with a bleeding diathesis and those on anticoagulants. Large doses of fish liver oils may result in toxic levels of vitamins $A$ and $D^{37}$ or accumulation of harmful lipid peroxides. ${ }^{2}$ Certain fish oils may contain erucic acid (22:1n9), which can have toxic effects on cardiac muscle. $^{2}$

\section{Conclusions}

We have tried to put the role of fish oil in psoriasis into perspective. It is minimally to modestly effective as a monotherapy when used in high doses with dietary control. Further studies are needed to determine if other conventional therapies may be helpful adjuncts to fish oil therapy. It also may be a desirable candidate for combination use with retinoids or cyclosporin A.

\section{Acknowledgments}

Research assistants Mr. David C. Tellner and Ms. Caren R. Frutig helped with the study. Ms. Amy J. Rundquist typed the manuscript. R. P. Scherer provided the Max-EPA ${ }^{R}$ fish oil and placebo olive oil capsules. Westwood Pharmaceuticals Inc., Buffalo, N.Y., supplied the betamethasone diproprionate cream.

\section{References}

1. Schacky CV. Prophylaxis of atherosclerosis with marine omega-3 fatty acids. Ann Intern Med. 1987;107:890-899.

2. Isseroff RR. Fish again for dinner! The role of fish and other dietary oils in the therapy of skin disease. J Am Acad Dermatol. 1988; $19: 1073-1080$.

3. Ziboh VA, Cohen KA, Ellis CN, et al. Effects of dietary supplementation of fish oil on neutrophil and epidermal fatty acids. Arch Dermatol. 1986;122:1277-1282.

4. Maurice PDL, Allen BR, Barkley ASJ, et al. The effects of dietary supplementation with fish oil in patients with psoriasis. $\mathrm{Br}$ J Dermatol. 1987; 117:599-606.

5. Bittiner SB, Tucker WFG, Cartwright I, et al. A double-blind, randomized, placebo-controlled trial of fish oil in psoriasis. Lancet. 1988;1:378-380.

6. Bjorneboe A, Smith AK, Bjornboe G-E A, et al. Effect of dietary supplementation with n-3 fatty acids on clinical manifestations of psoriasis. Br J Dermatol. 1988;118:77-83. 
7. Kettler AH, Baughn RE, Orengo IF, et al. The effect of dietary fish oil supplementation on psoriasis. J Am Acad Dermatol. 1988; 18:1267-1273.

8. Gupta AK, Ellis CN, Tellner DC, et al. Double-blind, placebocontrolled study to evaluate the efficacy of fish oil and low dose ultraviolet $\mathrm{B}$ in the treatment of psoriasis. $\mathrm{Br}$ J Dermatol. 1989;120:801-807.

9. Kragballe K, Fogh K. A low-fat diet supplemented with dietary fish oil (Max-EPA) results in improvement of psoriasis and in formation of leukotriene $B_{5}$. Acta Derm Venereol (Stockh). 1989;69:23-2E.

10. Bjorneboe A, Soyland E, Bjorneboe G-E, et al. Effect of dietary supplementation with eicosapentaenoic acid in the treatment of atopic dermatitis. Br J Dermatol. 1987;117:463-469.

11. Voorhees JJ. Leukotrines and other lipoxygenase products in the pathogenesis and therapy of psoriasis and other dermatoses. Arch Dermatol. 1983;119:541.

12. Burton JL. Dietary fatty acids and inflammatory skin disease. Lancet. 1989;1:27-30.

13. Kunkel SL, Chensue SW, Phan SH. Prostaglandins posttranscriptionally inhibit monocyte expression of interleukin 1 activity by increasing intracellular cyclic adenosine monophosphate. J Immunol. 1986;135:1153.

14. Sauder DN, Stanuli-Praeger BM, Gilchrest BA. Autocrine growth stimulation of human keratinocytes by epidermal cell-deprived thymocyteactivating factor: Implications for skin aging. Arch Dermatol. 1980;280:71-76.

15. Cooper KD, Hammerberg C, Baadsgaard O, et al. Reduced IL-1 activity in prsoriatic skin: decreased IL-a and increased nonfunctional IL-1b (submitted for publication).

16. Endres S, Ghorbani R, Kelley VE, et al. The effect of dietary supplementation with $n-3$ polyunsaturated fatty acids on the synthesis of interleukin-1 and tumor necraosis factor by mononuclear cells. N Engl J Med. 1989;320:265-271.

17. Singer $P$, Wirth $M$, Voigt $S$, et al. Blood pressure- and lipid-lowering effect of mackerel and herring diet in patients with mild essential hypertension. Atherosclerosis. 1985;56:223-235.

18. Mehta JL, Lopez LM, Lawson D, et al. Dietary supplementation with omega-3 polyunsaturated fatty acids in patients with stable coronary disease: effects on indices of platelet and neutrophil function and exercise performance. Am J Med. 1988;84:45-52.

19. Bennett WM, Elzinga L, Kelley V. Pathophysiology of cyclosporine nephrotoxicity: role of eicosanoids. Transplant Proc. 1988;20:628-633.

20. Humes HD, Coffman T, Halderman $H$, et al. Cyclosporine nephrotxicity. Transplant Proc. 1988;20:833-840.

21. Von Lossonczy TO, Ruiter A, Bronsgeest-Schoute $\mathrm{HC}$, et al.
The effect of a fish diet on serum lipids in healthy human subjects. Am J Clin Nutr. 1978;31:1340-1346.

22. Harris WS, Connor WE, Goodnight SH. Dietary fish oils, plasma lipids and platelets in man. Prog Lipid Res. 1981;20:75-79.

23. Sanders TAB, Vickers $M$, Haines AP. Effect on blood lipids and haemostasis of a supplement of cod-liver oil, rich in eicosapentaenoic and docosahexaenoic acids, in healthy young men. Clin Sci. 1981;61:317-324.

24. Bronsgeest-Schoute $H C$, van Gent CM, Luten JB, et al. The effect of various intakes of w3 fatty acids on the blood lipid composition in healthy human subjects. Am J Clin Nutr. 1981;34:1752-1757.

25. Yetiv JZ. Clinical applications of fish oil. JAMA. 1988;260:665670.

26. Marsden JR. Effect of dietary fish oil on hyperlipidaemia due to isotretinoin and etretinate. Hum Toxicol. 1987:6:219-222.

27. Ashley JM, Lowe NJ, Borok ME, et al. Fish oil supplementation results in decreased hypertriglyceridemia in patients with psoriasis undergoing etretinate or acitretin therapy. J Am Acad Dermatol. 1988;19:76-82.

28. Gorlin R. The biological actions and potential clinical significance of dietary $w-3$ fatty acids. Arch Intern Med. $1988 ; 148: 2043-2048$

29. Goodnight SH, Harris WS, Connor WE. The effects of dietary w3 fatty acids on platelet composition and function in man: A prospective, controlled trial. Blood. 1981;58:880-885.

30. Sanders TAB, Roshanai $F$. The influence of different types of $w 3$ polyunsaturated fatty acids on blood lipids and platelet function in healthy volunteers. Clin Sci. 1983;64:91-99.

31. Knapp HR, Reilly IAG, Alessandrini $P$, et al. In vivo indexes of platelet and vascular function during fish oil administration in patients with atherosclerosis. N Engl J Med. 1986;314:937942.

32. Terano T, Hirai A, Hamazaki T, et al. Effect of oral administration of highly purified eicosapentaenoic acid on platelet function, blood viscosity and red cell deformability in healthy human subjects. Atherosclerosis. 1983;46:321-331.

33. Woodcock BE, Smith E, Lambert WH, et al. Beneficial effect of fish oil on blood viscosity in peripheral vascular disease. $\mathrm{Br}$ Med J. 1984;288:592-594

34. Kremer JM, Bigauoette J, Michalek AV, et al. Effects of manipulation of dietary fatty acids on clinical manifestations of rheumatoid arthritis. Lancet. 1985;1:184-187.

35. Darlington LG, Ramsey NW, Mansfield JR. Placebo-controlled, blind study of dietary manipulation therapy in rheumatoid arthritis. Lancet. 1986;1:236-238.

36. Ritter JM, Taylor GW. Fish oil in asthma. Thorax. 1988:43:8183.

37. Fish oil for the heart. Med Lett Drugs Ther. 1987;29:7-9.

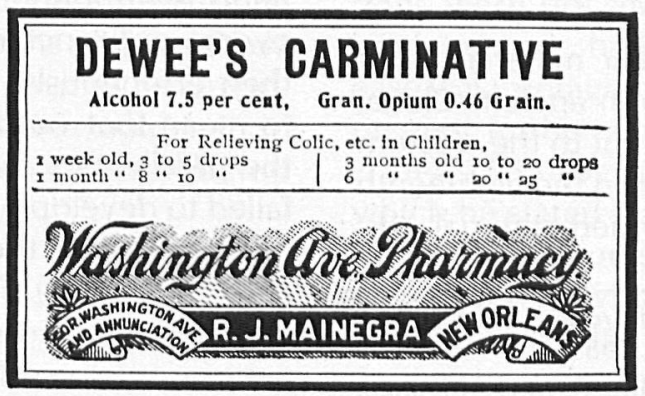

From the collection of "La Pharmacie Francaise," New Orleans, Louisiana, Mr. Ben Bavly, Curator. 
This document is a scanned copy of a printed document. No warranty is given about the accuracy of the copy. Users should refer to the original published version of the material. 